\title{
Regeneration of Haploids in Oil Seed through Embryonic Microspore
}

\author{
Shahina A. Nagoo ${ }^{*}$, GulZaffar ${ }^{2}$, Sabina Naseer ${ }^{4}$, N.A. Dar ${ }^{3}$, \\ Sabia Bashir ${ }^{4}$, M. Altaf Wani ${ }^{4}$ and Shabina Majid ${ }^{4}$ \\ ${ }^{1}$ Division of GPB FoAWadura, SKUAST-K, India \\ ${ }^{2} D A R S$-Budgam SKUAST-K, India \\ ${ }^{3}$ Saffron Research Station, SKUAST-K, India \\ ${ }^{4}$ SKUAST-K, India \\ *Corresponding author
}

\begin{tabular}{|l|}
\hline Ke y w or d s \\
$\begin{array}{l}\text { Haploids, Brassica- } \\
\text { rapa, Shoot/ Root } \\
\text { regeneration }\end{array}$ \\
\hline Article Info \\
\hline $\begin{array}{l}\text { Accepted: } \\
\text { 22 May 2018 } \\
\text { Available Online: } \\
\text { 10 June 2018 }\end{array}$ \\
\hline
\end{tabular}

\section{Introduction}

Brown sarson is the major oilseed crop of valley grown on about 50 thousand hacters and fits in rotation with Rice crop. No significant breakthrough in enhancing the existing productivity levels $(7-8 \mathrm{q} / \mathrm{ha})$ and oil quality has been possible due to lack of variability in the available germplasm (Singh et al 2007). Operation of self incompatibility 
limits production of homozygous inbred lines through conventional breeding procedures, necessitating biotechnological interventions for accelerating breeding progress and generating genetic variability useful for developing high yielding varieties.The efficient production of haploid and double haploid (DH) plants from anther or microspore culture has become an important new tool for Brassicabreeders. But limited research has been conducted with Brown Sarson (Brassicarapa) as it is more recalcitrant in cell and tissue culture than other Brassicas. The present investigation was undertaken to develop a protocol for production of $\mathrm{DH}$ Plants in B.rapa from anderogenic embryos.

\section{Materials and Methods}

Flowered buds 2.5 to $2.7 \mathrm{~mm}$ long representing late uninucleate stage were collected from field grown plants of 2Brassica compestris varieties namely KOS-1 and KS101, subjected to low temperature pretreatment and surface sterilized with $1 \%$ sodium hypochloride for 8 to 10 minuts ( $\mathrm{Gu}$ et al 2004). Anthers were picked from buds and cultured on MS medium suplimented with various concentrations of 2,4-D and NAA for embryogenic callus induction.For regenerations from embryogenic callus MS media suplimented with various concentrations of auxins and cytokinens were used. Root induction in regenerated shoots was tried using various concentrations of IBA. The cultures were incubated at $22+-2^{0} \mathrm{C}$. Root tip mitotic chromosome counts were used to confirm haploid nature of Anther derived regenerates and double haploidy level induced through use of various concentrations of colchicines was detected cytologically using pollen mother cell (PMC).

\section{Results and Discussion}

Maximum percentage of aseptic culture was achieved in KS-101followed by KOS1genotypes.Callus initiation was maximum (32.62) when anthers were given pretreatment (chilling treatment) temperature of $4^{0} \mathrm{C}$ for seven days (Zhang et al 2006,Kumari and Singh 2014). Maximum percentage of callus initiation (22.48) was observed in KS-101 genotype followed by $\mathrm{KOS}-1(\mathrm{Gu}$ etal 2003)[Table 1].

Maximum number of anthers per 100 buds forming callus was observed in Murashige and Skoog medium 1962, supplemented with 2,4-D $\quad(1.0 \mathrm{mg} / \mathrm{lit})$ and NAA $(0.5 \mathrm{mg} / \mathrm{lit})$ (36.60). Days taken to initiate callusing was minimum (22.48 days) when induction medium (MS medium) was supplemented with BA (1.5 mg/lit) and 2,4-D (1.0 mg/lit) (Li etal., 2005).

Table.1 Effect of pre treatment of anthers on callus initiation

\begin{tabular}{|l|l|l|l|l|l|l|l|}
\hline Genotype & T1 & T2 & T3 & T4 & T5 & T6 & Mean \\
\hline KOS-I & $\begin{array}{l}23.86 \\
(29.22)\end{array}$ & $\begin{array}{l}21.88 \\
(27.87)\end{array}$ & $\begin{array}{l}22.88 \\
(28.55)\end{array}$ & $\begin{array}{l}30.25 \\
(33.35)\end{array}$ & $\begin{array}{l}23.02 \\
(28.65)\end{array}$ & $\begin{array}{l}21.01 \\
(27.26)\end{array}$ & $\begin{array}{l}\mathbf{2 3 . 8 1} \\
(\mathbf{2 9 . 1 5})\end{array}$ \\
\hline KS-IOI & $\begin{array}{l}22.03 \\
(27.97)\end{array}$ & $\begin{array}{l}20.98 \\
(27.24)\end{array}$ & $\begin{array}{l}21.98 \\
(27.94)\end{array}$ & $\begin{array}{l}45.78 \\
(42.57)\end{array}$ & $\begin{array}{l}23.34 \\
(28.88)\end{array}$ & $\begin{array}{l}19.23 \\
(25.99)\end{array}$ & $\begin{array}{l}\mathbf{2 5 . 5 5} \\
\mathbf{( 3 0 . 1 0})\end{array}$ \\
\hline
\end{tabular}


Table.2 Influence of growth regulators on number of plants regenerated

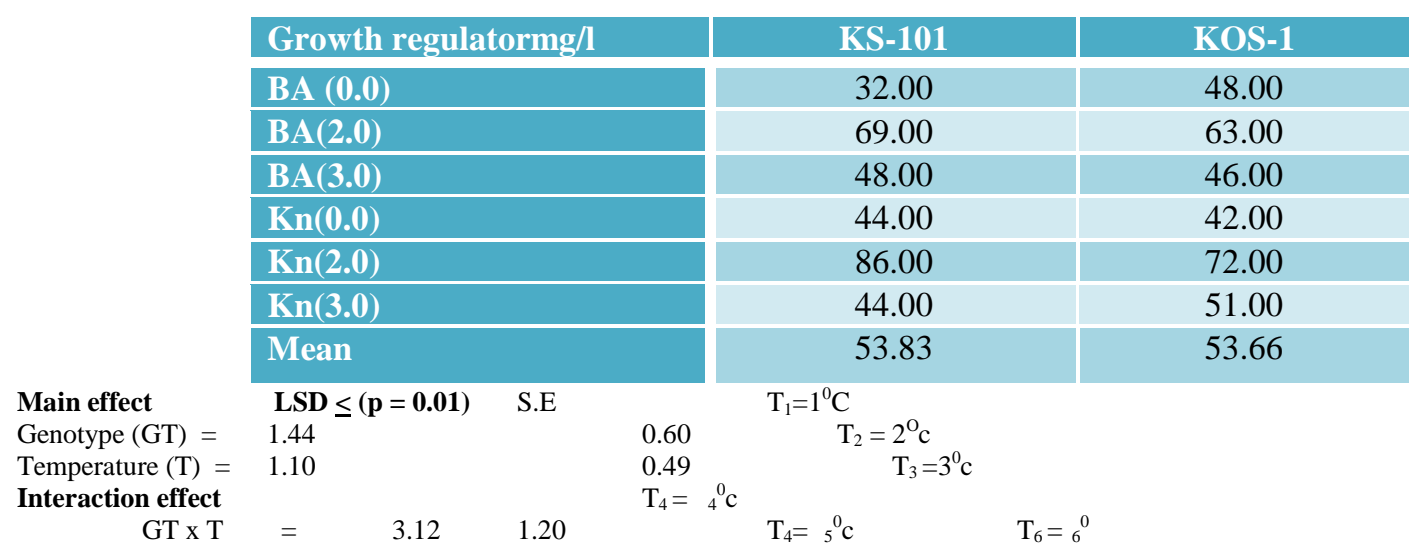

Table.3 Influence of growth regulators on per cent in vitro rooting of micro shoots

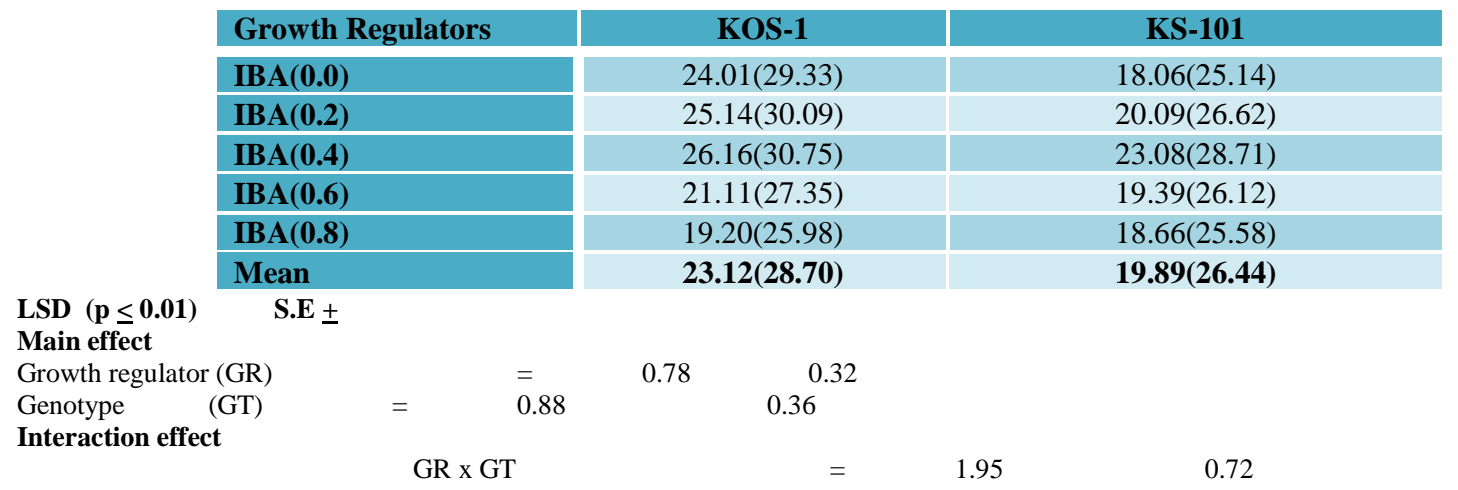

Table.4 Influence of different treatment combinations and media formulations on haploid frequency (Per cent)

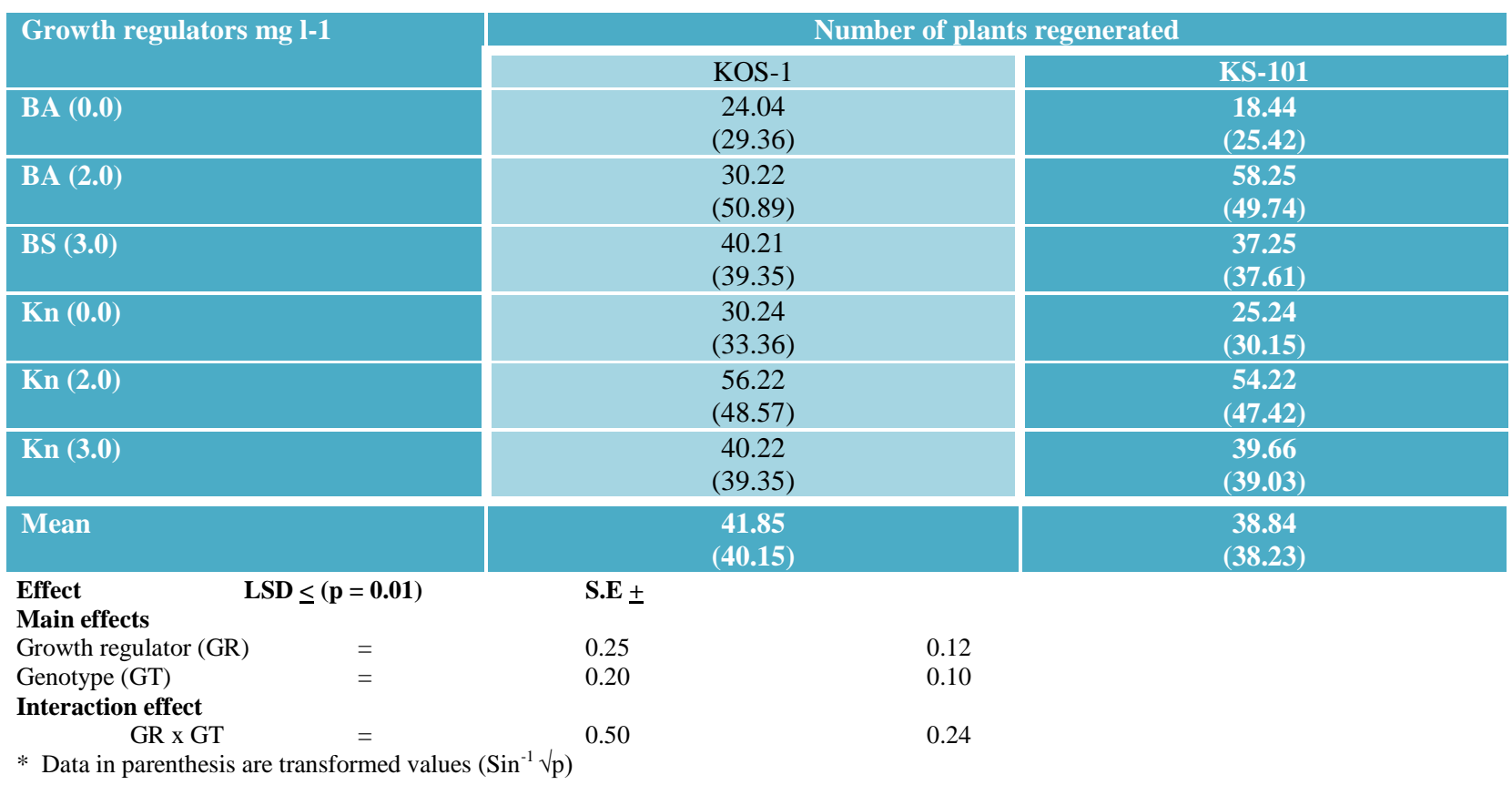


Highest number of shoots per explants of proliferated cultures (86.00) was achieved (Natalajietal 2006) [Table 2] when MS full strength medium was supplemented with Kn (2.0 $\mathrm{mg} / \mathrm{lit})$ followed by the use of $\mathrm{BA}(2.0$ $\mathrm{mg} / \mathrm{lit}$ (69.00), highest number of shoots was regenerated in KS-101(53.83)followed by KOS1(53.66). These shoots devoid of any callus, were sub-cultured on rooting medium containing various concentrations of auxin (IBA). Maximum rooting $(30.75 \%)$ was achieved when MS medium was supplemented with $0.4 \mathrm{mg} / \mathrm{lit}$ IBA[Table 3$]$.

Root tip mitosis chromosome counts revealed maximum percentage of haploid frequency in KOS-1(41.85\%) followed by KS-101(38.84\%) (Natalijaetal 2004)[Table 4]. Diploidization of haploid plants was carried out by using different concentrations of colchicines for different time durations (Dwarkeshetal 2006).Maximum doubling efficiency was obtained when roots of plantlets were submerged in $20 \mathrm{mg} /$ lit colchicines for 2 hours and about 40-45 per cent diploidization was achieved. In conclusion, protocol developed for the production of double haploid plants through endrogenesis offers a viable alternative to develop homozygous lines for further use in the development of hybrid/synthetic varieties having higher yield, better quality and tolerance to stresses.

\section{References}

Dwarkesh, S., Parihar.,Sanjit. A. 2006. Microspore culture for induction of doubled Haploidy in B. juncea and B.rapa Journal of Experimental Botany, 35:1668-1678.

Gu, H.H., Zhou, W.J., Hagberg, P. 2003. High frequency spontaneous production of doubled haploid plants from microspore culture in Brassicarapa ssp. Chinensis. Ehuphytica, 134: 239-245.
Gu, H.H., Tang, G.X., Zhang, G.Q. Zhou. W.J. 2004.Embryogenesis and plant regeneration from isolated microspores of winter cauliflower (Brassicaoleracea var. botrytis).Journal of Zhejiang University (Agriculture Life Science), 30: 34-38.

Kumari.P and Singh. A.K., 2014.Effect of cold pre-treatment on anther culturein different Brassicagenotypes.AsianJ. Bio. Sci. 9 (2) Oct.2014, 156-160.

Li, H.Z., Zhou, W.J. Zhang, Z.J., Gu, H.H., Takeuchi, Y., Yoneyama, K. 2005. Effect of $\gamma$-radiation on development yield and quality of micro-tubers in vitro in Solanumtuberosum L. BiologiaPlantarium, 49: 625-628.

Murashige,T. and Skoog, F. 1962. A revised medium for rapid growth and bioassays with tobacco tissue culture.Plant physiology, 15; 473-479.

Natalija,H., Hegberg,P., Zhou, W.J. 2004. Embryogenesis, callogenesis and plant regeneration from anther culture of spring rape (B. napus L.). PlantGrowth Regulation, 32; 127-133.

Singh, V., Singh, S.P., Singh, H., Hegde, D.M. and Tahir, T.A. 2007. Past progress present scenario, nutritional value and strategies to enhance yield potential of rapeseed-mustard: an overview, Indian Journal of Crop Science 2(2): 245-257.

Zhang, G.Q., Zhang, D.Q., Tang, G.X., He, Y., Zhou, W.J.2006. Plant development from microspore-derived embryos in oilseed rapa as affected by chilling, dessication and cotyledon excision. BiologiaPlantarum, 50: 180-186.

\section{How to cite this article:}

Shahina A. Nagoo, GulZaffar, Sabina Naseer, N.A. Dar, Sabia Bashir, M. Altaf Wani and Shabina Majid 2018. Regeneration of Haploids in Oil Seed Through Embryonic Microspore. Int.J.Curr.Microbiol.App.Sci. 7(06): 3336-3339. doi: https://doi.org/10.20546/ijcmas.2018.706.390 